\title{
HEGEL E O MODERNO CONCEITO DE SOCIEDADE CIVIL ${ }^{1}$
}

\author{
Hegel and the modern concept of civil society
}

\author{
Cesar Augusto Ramos
}

Doutor em Filosofia Política pela UNICAMP. Professor do Programa de Pós-graduação em Filosofia da PUCPR, Curitiba, PR - Brasil, e-mail: cauramos@uol.com.br

\begin{abstract}
Resumo
$\mathrm{O}$ artigo tem por objetivo analisar o conceito hegeliano de sociedade civil (burguesa). Este conceito consolida, em termos filosóficos e segundo a estrutura da Filosofia do Direito de Hegel, a tendência histórica moderna de separação entre a esfera civil (privada e de fundo econômico) e a esfera do Estado (pública e com sentido político). Ao propor esta distinção como reflexo da sociedade moderna, Hegel afasta-se da concepção política do Direito Natural. Por fim, a análise hegeliana revela a presença inevitável de contradições no âmbito da própria sociedade civil, postulando, assim, a sua superação em direção ao Estado.
\end{abstract}

Palavras-chave: Sociedade civil; Hegelianismo; Estado.

\begin{abstract}
The aim of this article is to analyze the Hegelian concept of civil society (bourgeois). This concept consolidates, in philosophical terms and according to the structure of Hegel's Philosophy of Right, the modern historical tendency of separation between the civil sphere (private and of

1 O presente artigo é o resultado da revisão de alguns aspectos analisados no capítulo $A$ sociedade civil-burguesa e a esfera privada do indivíduo, do meu livro RAMOS, C. A. Liberdade subjetiva e estado na filosofia política de Hegel. Curitiba: UFPR, 2000.
\end{abstract}


economical background) and the State (public and with a political sense). Proposing that distinction as a reflex of modern society, Hegel moves away from the political conception of Natural Rights. Lastly, the Hegelian analysis reveals the inevitable presence of contradictions in the ambit of the civil society itself, thus, postulating its overcoming towards the State.

Keywords: Civil society; Hegelianism; State.

Na tradição da escola do Direito Natural Moderno, ${ }^{2}$ a sociedade civil era vista como uma comunidade juridicamente organizada e politicamente soberana em oposição ao estado de natureza, no qual os homens, em conjunto ou isoladamente, teriam vivido de forma primitiva e sem a ação coercitiva de leis civis que apenas um poder comum e soberano pode promover e garantir. Com a constituição deste último, o status político dos homens passa a ser civil e a associação entre eles forma uma societas civilis. Reunidos pelo contrato, os indivíduos submetem-se ao governo desta sociedade, qualificada como Estado, e que tem por objetivo garantir a paz, proteger a propriedade privada e o direito natural dos indivíduos, sobretudo, a liberdade. A sociabilidade que o contrato instaura revela-se política, na medida em que o Estado nada mais é do que a expressão civil de uma forma de associação que se distingue do estado de natureza. A sociedade que não possui esta estrutura é apenas um agrupamento de indivíduos, sociáveis ou não, limitados às inconveniências do direito natural.

Os estudos de Riedel demonstraram que a expressão aristotélica koinomia politiké, mais tarde traduzida por societas civilis, serviu - junto com o termo res publica - para designar o Estado. O termo latino indicava a unidade da societas com a civitas.

2 Esta escola compreende diversos filósofos, como Hobbes, Rousseau, Leibniz, Locke, Kant, Fichte, como também juristas filósofos, como Pufendorf, Barbeyrac, Burlamaqui, Althusius, Thomasius. A obra de A. Grotius De iure belli ac pacis (1625) pode ser considerada como marco inaugurador dessa escola que se ramifica com diferenças importantes, sem, contudo, eliminar sua unidade segundo características comuns, até Hegel exclusive. Marcada pelo individualismo, o Direito Natural moderno apresenta características mais ou menos comuns: a admissão de uma origem natural da liberdade individual que se manifesta num estado de natureza determinando os indivíduos como iguais e livres; a contraposição entre este estado de natureza e a sociedade civil, a instituição artificial do poder do estado por meio de uma hipótese contratual que opera a passagem do estado de natureza de natureza para o Estado civil; o racionalismo como método de investigação e como ponto de partida para a dedução do estatuto natural e depois civil (político) dos indivíduos. 
Assim, pode-se dizer que 'sociedade civil' no sentido europeu antigo, é um conceito político da tradição, e constitui a categoria fundamental, central de um mundo político no qual 'estado' e 'sociedade' não estão ainda separados, mas formam antes a união em si homogênea do poder da sociedade civil-política, união que se funda sobre a esfera 'econômica' do trabalho doméstico-servil, da escravidão ou da servidão da gleba e do serviço e dessa se destaca. (RIEDEL, 1975, p. 148).

No seu uso medieval, o vocábulo civil identifica-se com o político. Modernamente, essa identificação permanece ainda em Hobbes, Spinoza, Locke, Kant, para os quais o Estado é a forma jurídica e política em que a sociedade civil se constitui, com ele se identificando. Na medida em que a sociedade moderna evolui no sentido de propiciar ao indivíduo um lugar próprio (privado) para o desenvolvimento de sua vida particular e realização dos seus interesses e carências, a condição do homem como membro da sociedade civil torna-se problema e objeto de atenção para a filosofia política. Para além da análise da tradição do Direito Natural, ela pretende, doravante, apreender o moderno conceito de sociedade vinculado às práticas privadas (civis), notadamente aquelas de fundo econômico, e que marcam profundamente o campo das relações sociais do mundo burguês.

Ao destacar a contraposição (ignorada pela tradição) entre a esfera política e a esfera não-política, a expressão "sociedade civil" adquire, já no século XVIII e, sobretudo, no começo do século XIX, um sentido mais específico. Ela passa a designar o espaço privado (não-político) que caracteriza as relações sociais e econômicas da sociedade burguesa. Esta concepção implica, na observação de Bobbio, ver na sociedade civil um aspecto "negativo": aquilo que está fora do âmbito do poder estatal, a "esfera das relações sociais não reguladas pelo Estado". Positivamente, diz Bobbio, a sociedade civil é vista como "lugar onde surgem e desenvolvem-se os conflitos econômicos, sociais, ideológicos, religiosos, que as instituições estatais têm o dever de resolver ou através da mediação ou através da repressão" (BOBBIO, 1987, p. 35-36).

É, precisamente, esta nova perspectiva histórica que o conceito hegeliano de sociedade civil pretende apreender, traduzindo-a especulativamente segundo as categorias conceituais da Filosofia do Direito. A concepção hegeliana visa, deste modo, superar (no sentido do termo Aufhebung que o filósofo emprega) a tradição clássica que identificava a societas civilis com a civitas. Para Hegel, esta sociedade circunscreve o interesse privado do bourgeois, da produção econômica e do trabalho. Portanto, como esfera distinta do Estado. Hegel é sensível ao fato da despolitização da sociedade civil moderna em favor do econômico, deslocando o político para o Estado e centralizando a sociedade civil-burguesa nas atividades privadas e econômicas típicas do homem moderno. 
A Filosofia do Direito designa as relações sociais e econômicas dos indivíduos não mais no seu significado político (civil).

O uso do termo sociedade civil-burguesa (bürgerliche Gesellschaft) para Hegel não indica apenas o caráter civil do segundo momento da vida ética (Sittlichkeit) que se constitui em sociedade ao superar a determinação imediata da família. Significa, também, e principalmente, o caráter burguês dessa sociedade segundo sua forma de organização social e econômica. Hegel afasta-se da tradição da filosofia do Direito Natural e compreende a sociedade civil-burguesa não mais como a sociedade política, mas como sociedade dos indivíduos burgueses associados segundo interesses econômicos. O termo alemão Bürger denota tanto o civil como o burguês, mas o filósofo consagra essa expressão para o membro da sociedade civil-burguesa (als bourgeois), e não para o citoyen membro da sociedade política.

$\mathrm{O}$ abandono do antigo conceito de societas civilis ocorre, fundamentalmente, pela atenção que Hegel dispensa à economia política inglesa e à revolução econômica industrial e pela valorização da categoria do trabalho centrada na liberdade subjetiva dos indivíduos. A evolução do conceito de sociedade civil-burguesa na obra de Hegel demonstra, desde a juventude, a preocupação com as relações da economia com a sociedade, relações essas que se restringirão àquilo que o filósofo mais tarde irá chamar de sociedade civilburguesa, termo que adquire importância decisiva a partir das Lições de Filosofia do Direito nos semestres de inverno de 1818-19.3

3 No período de Berna (1793-1796), o jovem Hegel lê a obra de Sir James Steuart An inquiry into the principles of political economy (1767). Segundo P. Chamley, Hegel utilizou a tradução alemã desta obra (Untersuchung der Grundzätze der Staats-Wirtschaft) feita por Christoph Friedrich Schott e editada por Cotta nos anos de 1769-1772 em Tübingen. Segundo Chamley, a influência dos Inquiry foi ainda mais ampla, compreendendo todo idealismo alemão. Hegel encontrou em Steuart "a dialética das necessidades e do trabalho livre; o jogo da concorrência entre os produtores e consumidores; o mecanismo da socialização do progresso, o papel da moda, do luxo, da moeda, a antecipação das necessidades pelos produtores, todas essas análises da Staastwirtschaft são transpostas por Hegel à sua doutrina" (CHAMLEY, P. Les origines de la pensée économique de Hegel. In: Hegel-Studien, Band 3. Paris, 1965. p. 251-252). "Tal foi o impacto criado pela leitura desse estudo - relata Avineri a propósito da obra de Steuart - que Hegel escreveu um longo comentário ao livro de Steuart, o qual está agora perdido, embora Rosenkranz ainda se reporta de ter visto o manuscrito em 1840" (AVINERI, S. Hegel's theory of the modern state. Cambridge: Cambridge University Press, 1972. p. 5). Também a obra de Adam Smith Inquiry into nature and the causes of the wealth of the nations (London, 1776), traduzida para o alemão por Garve em 1795-1796, influencia Hegel na compreensão das categorias econômicas presentes na Filosofia do Direito. Mais recentemente, N. Waszek procurou mostrar que a relação entre a economia política e Hegel é mais ampla, compreendendo a influência do scottisch enlightenment. D. Hume, A. Smith, A. Ferguson, J. Steuart influenciam o modelo econômico da sociedade civil hegeliana como sistema social-econômico marcado pelas necessidades particulares do homem, pelo trabalho humano e pelos meios igualmente particulares de satisfazê-las (WASZEK, N. The scottish enlightenment and Hegel's account of 'Civil Society'. Boston: Kluwer, 1988). 
Contudo, o reconhecimento do indivíduo da economia política não é de imediato aceito pelo jovem Hegel. Nos escritos do assim chamado Sistema da Eticidade, a vida (ética e política) grega fornecia o princípio de uma identidade substancial orgânica para a sua teoria, e a Política de Aristóteles servia de parâmetro teórico para a recepção dos problemas econômicos e sociais trazidos pela economia política inglesa. A tentativa nostálgica do jovem Hegel de recuperar a "bela totalidade" grega como solução para os problemas da sociedade moderna deslocou o indivíduo da economia inglesa para uma eticidade grega restaurada, na qual o valor da liberdade subjetiva ficou obliterado em favor de uma visão holista da política. Este deslocamento acarretou a contradição entre o valor do agir ético-político do modelo aristotélico e o reconhecimento da importância do processo produtivo do trabalho na moderna economia política, tido como fundamental para a constituição e manutenção da sociedade. O desejo de restaurar na sociedade moderna o modelo de eticidade de inspiração platônicoaristotélica é, então, abandonado. No entanto, o jovem Hegel tentava, ainda, integrar os resultados da economia política na cultura antiga e assimilar as conquistas do mundo industrial moderno segundo o modelo político grego.

A partir dos escritos de Frankfurt (1797-1800), Hegel vai assimilando as categorias econômicas da economia política como elementos fundamentais para a compreensão da moderna sociedade e para a construção teórica do conceito de bürgerliche Gesellschaft. Os escritos de Frankfurt incorporam a concepção histórica do desenvolvimento econômico, atestando a importância dos processos produtivos da moderna sociedade capitalista com base no trabalho. Com a leitura da economia política inglesa, Hegel vai, pouco a pouco, assimilando a importância do indivíduo na sociedade burguesa, na qual ele apresenta-se imbuído de princípios de vida marcados pela liberdade individual e de valores de ascensão social diferentes da tradição.

Segundo Lukács, no período de Frankfurt ocorreu uma mutação no pensamento do jovem Hegel que começa a ver na sociedade burguesa "um dado básico e imutável". Em Berna, o encantamento juvenil com a vida política da pólis e a admiração pelo cidadão que realiza no Estado uma vida pública levaram a uma percepção homem privado em "claro sintoma da decadência" (LUKÁCS, 1976, p. 119). Em Frankfurt, Hegel dedica uma visível importância especulativa ao caráter privado do sujeito como membro da sociedade moderna e se preocupa com o sentido filosófico dos seus problemas e necessidades particulares. Nesse momento, diz Lukács, "Hegel parte real e diretamente do indivíduo, de suas vivências e destinos, e estuda logo as formas particulares da sociedade burguesa referindo-se à sua influência nesse destino individual, à 
sua interação com ele" (LUKÁCS, 1976, p. 119). Desde então, a sensibilidade aos problemas econômicos e sociais da sociedade burguesa de sua época, bem como a valorização da filosofia da subjetividade de Kant e de Fichte, contribuem para a representação da filosofia política hegelina, tendência essa que culmina nos escritos da maturidade.

A Filosofia do Direito de 1821 supera, definitivamente, o esquema juvenil de análise da modernidade segundo o modelo clássico. Trata-se, agora, de apreendê-la especulativamente de acordo com a verdade dos tempos modernos. Após o "abandono" do modelo clássico, com o rompimento do esquema teórico tradicional da filosofia prática-política e a aceitação do princípio da liberdade subjetiva das sociedades modernas, Hegel passa a compreender a sociedade civilburguesa como o lugar histórico-sistemático adequado às relações sociais e econômicas distintas da esfera do Estado, locus privilegiado do político.

A partir de então, a sociedade civil-burguesa e a sua compreensão pela economia política como "uma das ciências que encontrou na época moderna seu próprio terreno" (HEGEL, 1970, § 189, An.), constitui um marco histórico inarredável que a especulação filosófica deve desvendar, revelando a sua verdade em consonância com a realidade histórica dos tempos modernos. Nesta sociedade, o princípio da liberdade subjetiva, a emancipação do sujeito e a autonomia individual encontram solo concreto de efetiva manifestação e realização. Ela rompe não só com a tradição que prendia o indivíduo a vínculos de sangue da tradição, como também liberta o homem para si, para o seu interesse e para a sua própria atividade (trabalho). Com a sociedade civil-burguesa, o homem encontra-se livre, consigo mesmo, com sua própria capacidade e força numa esfera que é específica à sua liberdade de agir e de trabalhar segundo os interesses particulares.

Na estrutura especulativa da Filosofia do Direito, a sociedade civilburguesa ocupa o momento intermediário da eticidade, situando-se entre a família e o Estado. O § 157 desta obra, ao apresentar os momentos da substância ética, caracteriza a sociedade civil-burguesa como a

união dos membros enquanto singularidades independentes numa universalidade, portanto, formal mediante suas necessidades e por meio da constituição jurídica (Rechtsverfassung) como meio para a segurança das pessoas e da propriedade, e mediante uma ordem exterior para seus interesses particulares e comuns. (HEGEL, 1970, § 157).

Na Enciclopédia, ela é definida como a "totalidade relativa das relações relativas dos indivíduos como pessoas independentes, uns com os outros, numa universalidade formal” (HEGEL, 1969, § 517). 
$\mathrm{Na}$ análise de Ilting, a sociedade civil-burguesa na teoria de Hegel é:

Concebida como contexto das atividades individuais. Ela é criada por uma multiplicidade de indivíduos os quais, primeiramente, buscam seus próprios fins. Ao manterem múltiplas relações uns com os outros, eles se tornam por fim totalmente dependentes da várias condições dessa rede de suas ações, a qual eles mesmo ajudaram a produzir. Ela é primeiro, e antes de tudo, um 'sistema das necessidades e carências' (System der Bedürfnisse) onde cada um depende dos outros: as condições da produção na moderna sociedade industrial. (ILTING, 1971, p. 107).

Segundo Pelczynski (1984, p. 263):

a sociedade civil, para Hegel, era um aspecto do moderno Estado que emergiu da Europa ocidental no século dezoito e tornou-se notavelmente manifesto depois da Revolução Francesa de 1789. Era uma complexa rede altamente especializada de regras, instituições, agências, grupos, práticas e atitudes elaboradas dentro da organização legal e política da nação-estado, para satisfazer necessidades individuais e salvaguardar direitos individuais. Estava ligada com a concepção de um indivíduo abstrato, atomístico, perseguindo seu próprio interesse através do trabalho, da produção e dos contratos e gozando moral e juridicamente direitos garantidos à livre atividade na esfera econômica, social e cultural.

De início, é preciso destacar que o sentido da sociedade civilburguesa hegeliana deve ser apreendido na forma da sua apresentação histórica. A partir dessa evidência, deve-se buscar o significado especulativo que ela contém e que é preciso revelá-lo dentro de determinados parâmetros lógico-conceituais.

Do ponto de vista histórico, a presença do indivíduo na sociedade civil-burguesa está amparada no seu reconhecimento como sujeito livre, que deve ser considerado e respeitado na sua subjetividade. Ele se integra efetivamente como membro de uma unidade social, cujo sentido apenas modernamente se apresentou na caracterização de uma sociedade (civilburguesa): "a criação dessa sociedade civil-burguesa pertence, de resto, ao mundo moderno...” (HEGEL, 1970, § 182, Zus.). A novidade da filosofia política hegeliana consiste na tematização teórica de uma distinção atribuída à realidade histórica dos tempos modernos entre o bourgeois e citoyen, entre a sociedade civil-burguesa e o Estado. 
A liberdade burguesa é, com efeito, a privação do universal, princípio do isolamento. Mas esta liberdade - para bourgeois e citoyen não temos duas palavras - constitui um momento necessário que os antigos estados não conheciam e nem mesmo esta completa auto-suficiência das partes, mas [possuíam] uma maior auto-suficiência do todo - a vida orgânica superior. (HEGEL, 1986, p. 228).

A concepção elementar de que o "homem vale porque é homem e não porque seja judeu, católico, protestante, alemão ou italiano, etc.” (HEGEL, $1986, \S 209$, An) adquire densidade concreta apenas na sociedade civil-burguesa, a partir da modernidade. Esta sociedade põe concretamente a "universalidade" de um sujeito mediado pelas necessidades particulares dos demais agentes sociais. O carecimento individual incorpora-se num sujeito social que tem o reconhecimento dos outros, possuindo vigência universal na aceitação do princípio da igualdade e da liberdade, válido para todos.

É precisamente na moderna sociedade civil-burguesa que o homem - definido na determinação conceitual da liberdade subjetiva e no direito irrenunciável de agir segundo o seu arbítrio e interesse pessoal - determina-se como o cidadão burguês (Bürger). "No direito, o objeto é a pessoa; do ponto de vista da moralidade, o sujeito; na família, o membro da família; na sociedade civil-burguesa em geral, é o cidadão (como bourgeois)" (HEGEL, 1970, § 190, An). Esse indivíduo, sujeito da economia política, não é mais visto como citoyen, membro da societas civilis da tradição do jusnaturalismo moderno.

O bourgeois (Bürger) distingue-se como aquele indivíduo membro de uma forma de eticidade na qual ele se afirma como sujeito livre, e na qual ele realiza a satisfação das suas necessidades socialmente mediadas e reciprocamente determinadas segundo os mútuos carecimentos, dentro do universo econômico marcado pela divisão social do trabalho. Já o citoyen se traduz pelo estatuto político do indivíduo enquanto membro de uma forma superior de eticidade - o Estado. Esta oposição entre Estado e sociedade, público e privado, cidadão e burguês, vida política e vida social, revelou-se para Hegel como elemento típico da época moderna que a tradição política do jusnaturalismo não conseguiu apreender como novidade histórica. Com a modernidade emerge o indivíduo "civil", isto é, o sujeito constituído por uma sociabilidade que não é mais a da tradição da civitas.

Do ponto de vista conceitual, a sociedade civil-burguesa retrata o momento em que a eticidade apresenta uma universalidade formal de indivíduos singularmente caracterizados como sujeitos independentes e livres. Esses indivíduos estão unidos segundo a lógica da integração recíproca dos seus 
interesses e necessidades. Enquanto "ordem exterior" ou "estado exterior", a sociedade civil-burguesa tem por objetivo a proteção dos interesses particulares, da propriedade e da segurança das pessoas, bem como permitir a autosustentação dos indivíduos pelo trabalho. Nessa esfera, a substância ética surge na determinação da diferença presente no predomínio da particularidade que nega a identidade da universalidade ética imediata da família, revelando aquilo que Hegel chama de "perda da eticidade" (Verlust der Sittlichkeit). Este é o momento em que a substância ética mantém-se segundo a lógica do princípio da liberdade subjetiva da modernidade nas relações dos indivíduos uns com os outros. São relações sociais (civis) porque estabelecem entre os homens uma sociabilidade interdependente. Ela está marcada pelos carecimentos recíprocos e mediada pelo trabalho e pelo valor econômico que cada indivíduo representa para a sociedade como um todo.

A subsunção da necessidade individual, produzida pela sociedade civil-burguesa, torna a carência (natural), o direito da pessoa e a subjetividade moral - inicialmente definidos como pressupostos meramente abstratos - realidades efetivas na esfera privada da Sittlichkeit. A concepção abstrata do indivíduo, este pressuposto conceitual que aparece nas determinações do Direito Abstrato e da Moralidade (Moralität), configura-se concretamente e alcança sua realidade efetiva (Wirklichkeit) na sociedade civilburguesa, onde o homem surge como indivíduo privado (burguês), no sentido de uma singularidade que tem para si necessidades, desejos, carências, bem como a atividade econômica adequada para realizá-las: o trabalho individual na intersecção da sua divisão social.

A busca da auto-satisfação da maneira que mais convém ao indivíduo na esfera social que lhe é própria e, por isso mesmo, denominada de esfera privada, constitui o princípio predominante da sociedade civil-burguesa: a particularidade. A liberdade subjetiva revela-se neste princípio, no "direito do sujeito de encontrar sua satisfação na ação", previsto na ordem subjetiva da moralidade, e que tem na sociedade civil-burguesa o solo para a sua efetiva realização. Esta sociedade não se rege, portanto, por determinações rígidas de um sistema de castas ou de hierarquias sociais que modelam de forma perene a posição social dos seus membros, mas pela livre mobilidade dos agentes sociais segundo seus interesses e méritos. Nesta medida, ela surge como sociedade emancipada, referida apenas ao trabalho e à realidade auto-referente dos indivíduos associados. Nela, os sujeitos estão livres de toda e qualquer forma de servidão. São sujeitos autônomos porque se referem apenas a si próprios, à sua identidade formal (jurídica), à sua liberdade e às suas próprias necessidades. 
A determinação conceitual de um momento da Sittlichkeit como esfera privada do indivíduo (burguês) autônomo, emancipado dos vínculos familiares e que se assenta no princípio da particularidade, no "direito de desenvolver-se em todos os aspectos", é afirmada já no início da seção dedicada à sociedade civil-burguesa da Filosofia do Direito. "A pessoa concreta que é para si como fim particular, como um todo de carências (Bedürfnisse) e mistura de necessidade (Notwendigkeit) natural e de arbítrio, é um dos princípios da sociedade civil-burguesa" (HEGEL, 1970, § 182).

Nessa sociedade, o direito da particularidade apresenta-se concretamente sob a forma da satisfação das necessidades particulares dos indivíduos privados. "Como cidadãos (Bürger) deste estado (exterior), os indivíduos são pessoas privadas que têm como finalidade seu próprio interesse" (HEGEL, 1970, § 187). Trata-se de um estado exterior ou do entendimento (Verstandstaat) porque as relações entre os homens estão baseadas numa conexão social de exterioridade. Nessas relações, cada indivíduo é enfeixado num conjunto de operações sociais reguladas segundo a articulação "mecânica" do entendimento, desprovidas da força congregante de uma racionalidade imanente. Membro desse estado, o homem, na qualidade de indivíduo privado burguês (o Bürger als "bourgeois"), realiza aquilo que lhe convém pelo trabalho segundo suas próprias necessidades e desejos. Nessa medida, ele impõe para toda sociedade seu ponto de vista (privado): o de conceber a vida social e política como aquela baseada na liberdade subjetiva auto-referente e na promoção do seu bem-estar.

No entanto, a ênfase ao aspecto individual e emancipado do indivíduo inscreve-se numa forma social, onde a individualidade de cada homem efetiva-se pela interação dos sujeitos mediante o trabalho e pela atividade econômica da sociedade como um todo, a qual encontra sua regulação no direito privado. Ao tomar o homem enquanto homem, sujeito da sociedade civilburguesa, Hegel pretende, num primeiro momento, ressaltar o aspecto positivo da concepção abstrata do indivíduo que o entendimento constrói e que a sociedade revela como seu próprio fundamento. Num segundo momento, pretende indicar os limites e as contradições dessa sociedade.

A atomização dos indivíduos na sociedade civil-burguesa, portanto, não é absoluta. Enquanto momento da substância ética, essa sociedade não se reduz às relações interindividuais sem nenhuma conexão, e sem apresentar algum tipo de universalidade ou totalidade. Pelo fato de ser, precisamente, o "aparecer" da substancialidade ética, a sociedade civil-burguesa manifesta uma união de indivíduos independentes, naquilo que Hegel chama de universalidade formal. 
Nessa união, cada indivíduo está necessariamente em relação com um outro, de tal modo que a particularidade só se satisfaz por meio de outra. União que atesta uma relação de integralidade (Allheit) ou universalidade formal que se reporta às trocas individuais e à satisfação recíproca das necessidades. $\mathrm{O}$ momento da sociedade civil-burguesa, denominado de sistema das necessidades (System der Bedürfnisse), compreende a "mediação da necessidade e a satisfação do indivíduo singular pelo seu trabalho e pelo trabalho e satisfação das necessidades de todos os demais" (HEGEL, 1970, § 188).

A lógica da sociedade civil-burguesa atesta, portanto, um movimento voltado aos interesses egoístas dos indivíduos na persecução dos seus próprios fins. Mas, no conjunto, o bem de todos acaba por se realizar. A particularidade, circunscrita à universalidade formal, encontra sua determinação na relação com os outros pela mediação do trabalho (social) e pela reciprocidade das carências. Cada um buscando seu bem-estar trabalha, também, em favor dos outros: "promovendo meu fim promovo o universal que, por sua vez, promove meu fim" (HEGEL, 1970, § 184, Zus.). No processo de realização dos fins egoístas dos indivíduos, instaura-se um "sistema omnilateral de dependência" (System allseitger Abhängigkeit), onde o bem-estar, a subsistência e o direito de cada um se entrelaçam com o dos outros.

Esse "estado exterior" ou "ordem exterior" opera segundo a lógica da integração dos mútuos carecimentos, tal como o entendimento concebe. Assim, a sociedade civil-burguesa pode tornar-se objeto de conhecimento da economia política, que necessita operar com indivíduos separados e independentes como produtores e consumidores, mas que formam uma conexão social. Nessa medida, ela não pode ser confundida com a racionalidade interna do conceito de Estado.

Quando o Estado é representado como uma unidade de pessoas diversas, como uma unidade que é somente comunidade, o que se está denominando é, exclusivamente, a determinação da sociedade civil-burguesa. Muitos dos modernos teóricos do Estado não puderam trazer uma outra concepção de Estado. (HEGEL, 1970, § 182, Zus.).

Ao caráter relativo da substancialidade ética - que se mantém no seu momento de aparência sob a forma de um conjunto articulado dos interesses individuais e das vontades antagonistas da sociedade civil-burguesa - Hegel dá o nome de "estado exterior" (äusser Staat) ou "estado da necessidade e do entendimento" (Not und Verstandesstaat) para mostrar o aspecto da agregação dos indivíduos em um sistema atomístico de sociabilidade. 
Por isso, ela limita-se "ao aparecer da racionalidade (Scheinen der Vernünftigkeit) nesta esfera da finitude" (HEGEL, 1970, § 189), e move-se por relações exteriores e por determinações fixas, próprias da forma lógica do entendimento de conceber a realidade. Mas, assim como o entendimento constitui um começo para a razão, assim também o bourgeois da sociedade civil-burguesa constitui um momento antecipatório, uma imagem inicial, porém pobre da verdade e da riqueza do citoyen no Estado.

A caracterização da sociedade civil-burguesa pela particularidade egoísta dos indivíduos não lhe extrai o caráter de uma Sittlichkeit, não obstante o momento da perda da eticidade. Por isso, ela deve engendrar formas de sociabilidade que produzem a interdependência e a integração dos indivíduos. São formas ainda externas, calcadas na necessária dispersão dos indivíduos devido à divisão do trabalho e à diversidade profissional dos produtores, mas necessárias à atividade privada dos membros dessa sociedade. Na atomização dos indivíduos, essas formas favorecem a criação do sentimento de unidade social e de integração societária que se efetiva no Estado, mas que deve estar presente na esfera da sociedade civil-burguesa.

Enfim, a apreciação hegeliana da moderna sociedade civil-burguesa, retratada em categorias especulativas, fornece um diagnóstico da sua da forma econômica de produção. Essa análise, de cunho original e aderente aos novos tempos, pode ser resumida nos seguintes aspectos: 1) a ênfase no trabalho como categoria filosófica e econômica que especifica uma nova forma de produção de bens e de relação social; 2) a racionalização (abstração) do processo produtivo geral que inclui a abstração do próprio trabalho, das necessidades humanas e das relações sociais; 3) a necessidade psicológica de diferenciação social dos outros indivíduos em função da posse ou do consumo de bens diferenciados; 4) a noção de que a busca do interesse individual dos membros da sociedade converte-se, no conjunto, na realização das necessidades sociais coletivas; 5) o princípio da liberdade econômica como elemento gerador da desigualdade das riquezas.

Ao mesmo tempo em que a análise hegeliana ressalta a importância da moderna sociedade civil-burguesa, ela fornece elementos que atestam o seu caráter antagônico. Ao demonstrar que esta sociedade consigna o "campo de batalha dos interesses privados individuais de todos contra todos" (HEGEL, $1970, \S 289$, An), a referência ao elemento hobbesiano do bellum omnium contra omnes atesta o caráter de luta pela afirmação dos indivíduos na disputa social e econômica. Por isso, o sistema social tende à dispersão, ao desequilíbrio, à ruptura do tecido social que coloca em risco a própria pretensão de felicidade dos seus membros com base no princípio da liberdade subjetiva. Tal perspectiva 
leva Hegel à compreensão da insuficiência e limitações dessa sociedade marcada por contradições inerentes à sua natureza.

Uma das contradições diz respeito à forma como essa sociedade se constitui e se sustenta: a sua força consiste, precisamente, na sua própria expansão, uma vez que ela está livre de qualquer cerceamento na promoção do indivíduo para o gozo efetivo da liberdade subjetiva e para a afirmação autoreferente dos sujeitos burgueses. Subordinada à lógica da particularidade, a sociedade civil-burguesa mantém-se na exata medida em que ela luta para a sua preservação, o que conduz à exasperação do conflito e coloca em questão a sua própria finalidade: a satisfação da liberdade subjetiva, a felicidade e o prazer dos indivíduos que dela participam.

Uma outra contradição diz respeito às desigualdades econômicas, ou seja, à polarização na sociedade da riqueza-pobreza mediante a inevitável concentração dos recursos econômicos. São conseqüências perversas deste sistema econômico que tem por base filosófica a ética utilitarista da subordinação da liberdade à felicidade individual. No movimento da sua realização, esta última afigura-se sem nenhuma medida para a sua regulação, algo que é extremamente irracional. A desmedida com que a particularidade opera leva a enormes contradições e à total insegurança dos indivíduos na sociedade civil-burguesa. A contradição aqui se evidencia pela existência da miséria econômica de muitos ao lado da riqueza e da opulência de alguns. Hegel percebe que o estímulo à riqueza e à acumulação do dinheiro leva à voluptuosidade. A exigência ilimitada das necessidades, do consumo, do prazer, configura aquilo que Hegel chama de luxo (luxus) e a sua contrapartida, a miséria.

A tendência da situação social à multiplicação e à especificação indeterminada das necessidades, dos meios e dos gozos não tem limites, assim como a diferença entre as necessidades naturais e as cultivadas - o luxo - é igualmente um aumento infinito da dependência e da necessidade [...]. (HEGEL, 1970, § 195).

Com a finalidade de estabelecer controles à sociedade civil-burguesa sem, contudo, ferir os seus princípios e os seus direitos, e para que ela não sucumba aos seus efeitos autodestruidores, a Filosofia do Direito articula determinadas instâncias reguladoras internas à própria sociedade, sem as quais ela tornar-se-ia inviável. Essas instâncias - a administração da justiça, o poder de polícia e a corporação - operam na formação de um senso comum na própria esfera da particularidade, formando positivamente o indivíduo para a universalidade, antecipando, assim, a efetiva e concreta substancialidade política do Estado. 
Com efeito, sem a presença real do pressuposto do Estado, essas instâncias representam uma intromissão indevida e não se sustentam. De um modo especial, a corporação indica o sentido de uma disposição ética que educa o indivíduo para criar nele um sentimento que se opõe à contingência dos vínculos sociais e éticos, e à atomização dos interesses suscitados pelo isolamento e egoísmo. Os estamentos já apontavam para a necessidade de regulação (profissional). A regulamentação se generaliza e se formaliza juridicamente por meio da presença da lei, naquilo que Hegel denomina de "administração da justiça", e culmina em instituições (poder de polícia e corporações) que manifestam o caráter antecipatório do Estado na própria sociedade civil-burguesa.

$\mathrm{Na}$ verdade, o papel controlador destas instituições se traduz mais uma ação educativa e unificadora da sociedade, por si só insuficiente para conter as contradições sociais que demandam sua superação na esfera política da eticidade.

A particularidade para si, de um lado, enquanto satisfação para si que se estende em todas as direções de suas necessidades, do arbítrio contingente e do capricho subjetivo, destrói a si mesma em seu gozo e destrói seu conceito substancial; por outro lado, enquanto infinitamente excitada e na dependência geral de sua contingência externa e arbítrio, bem como restringida pelo poder da universalidade, é a satisfação contingente das necessidades tanto contingentes como necessárias. Nestas oposições e em seu entrelaçamento, a sociedade civil-burguesa oferece o espetáculo da dissolução, da miséria e da corrupção física e ética, comum a ambas. (HEGEL, 1970, § 185).

Ora, se a condição básica para o funcionamento dessa sociedade está calcada na liberdade subjetiva dos seus membros, resta saber se ela constitui a medida última da liberdade. Se, de um lado, a sociedade civil caracteriza-se pela emancipação dos vínculos de natureza, liberando o indivíduo para a consecução dos seus anseios, por outro lado, devido à lógica da sua própria constituição e reposição, a liberdade da sociedade civil-burguesa é ainda limitada, insuficiente para a realização do fim último do homem. A autonomia desta forma de Sittlichkeit representa apenas um momento - o do entendimento no processo de realização do conceito de liberdade.

O filósofo, a partir de uma análise interna da própria forma de funcionamento da sociedade civil-burguesa, chega à conclusão lógica de que ela não possui a medida da necessária universalidade que ela mesma prometia 
na dialética da sua constituição e funcionamento. Submetida às regras do entendimento e à lógica da má infinitude, ela se repõe a si própria num processo de constante crescimento que pode desencadear, se abandonada a si própria, a sua própria autodestruição. Urge, então, superar esse estado de desmedida, que põe em perigo o princípio da modernidade - a liberdade subjetiva. A forma superior da Sittllichkeit - a esfera política e pública do Estado - constitui uma necessidade conceitual para amparar e fundamentar o próprio espaço privado da sociedade civil-burguesa.

\section{Referências}

AVINERI, S. Hegel's theory of the modern State. Cambridge: Cambridge University Press, 1972.

BOBBIO, N. Estado, governo e sociedade. Para uma teoria geral da política. Tradução de M. A. Nogueira. Rio de Janeiro: Paz e Terra, 1987.

CHAMLEY, P. Les origines de la pensée économique de Hegel. In: HegelStudien, Band 3. Paris, 1965. p. 251-252.

HEGEL, G. W. F. Grundlinien der Philosophie Des Rechts Oder Naturrecht und Staatswissenschaft im Grundrisse. Werke 7. Frankfurt: Suhrkamp Verlag, 1970.

Enzyklopädie der Philosophischen Wissenschaften im Grundrisse (1830). Herausgegeben von F. Nicolin und O. Pöggefer. Hamburg: Felix Meiner, 1969.

Vorlesungen Über die Geschichte der Philosophie. II, Werke 19. Frankfurt: Suhrkamp Verlag, 1986.

ILTING, K. H. The Structure of Hegel's Philosophy of Right. In: PELCZYNSKI, Z. A. (Ed.). Hegel's political philosophy, problems and perspectives. Cambridge: Cambridge University Press, 1971.

LUKÁCS, G. El joven Hegel. Tradução de Manuel Sacristán. Barcelona: Grijalbo, 1976.

PELCZYNSKI, Z. A. Nation, civil society, state: Hegelian sources of the Marxian non-theory of nationality. In: PELCZYNSKI, Z. A. (Ed.). The State 
and civil society: studies in Hegel's political philosophy. Cambridge: Cambridge University Press, 1984.

RAMOS, C. A. Liberdade subjetiva e estado na filosofia política de Hegel. Curitiba: UFPR, 2000.

RIEDEL, N. Materialen zu Hegels Rechtsphilosophie. Band I e II, Herausgegeben von M. Riedel. Frankfurt: Suhrkamp, 1975.

WASZEK, N. The scottish enlightenment and Hegel's account of 'Civil Society'. Boston: Kluwer, 1988.

Recebido: 07/02/2008

Received: 02/07/2008

Aprovado: 29/02/2008

Approved: 02/29/2008 